\title{
COLORES Y SURCOS. UNA PROPUESTA METODOLÓGICA PARA EL ANÁLISIS DE LAS REPRESENTACIONES PLÁSTICAS DE LA REGIÓN DE FIAMBALÁ (TINOGASTA, CATAMARCA, ARGENTINA)
}

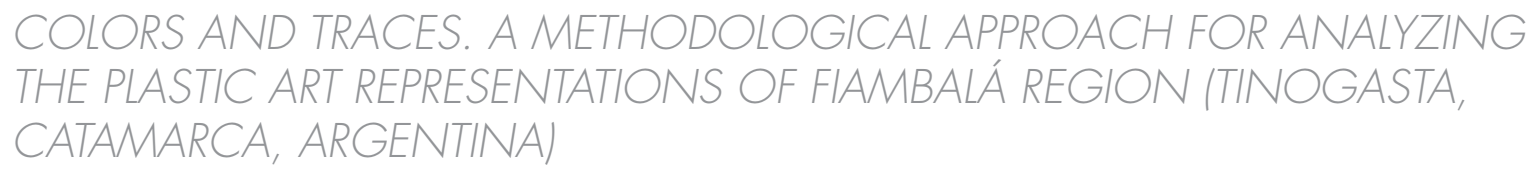

\section{MARA BASILE* \& NORMA RATTO* *}

Se presenta una propuesta metodológica que facilita el manejo y la integración de una muestra compuesta por una gran cantidad de representaciones plasmadas en soportes expresivos de características diferenciadas: piezas cerámicas y bloques rocosos. Se construyen variables analíticas confiables y no ambiguas para dar cuenta de los recursos visuales (caja de herramientas y modos de resolución) utilizados en la realización de las representaciones y así acceder a la interrelación que existe entre gestos, elementos y técnicas utilizadas en la resolución de las imágenes desplegadas en cada uno de los soportes expresivos. El procedimiento propuesto es ejemplificado por medio del análisis de una muestra de 772 representaciones del Período de Desarrollos Regionales o Período Intermedio Tardío (ca. 1200-1400 DC) plasmadas sobre piezas cerámicas y bloques rocosos de la región de Fiambalá.

Palabras clave: propuesta metodológica, representaciones en roca y cerámica, caja de herramientas, modos de resolución

We introduce a methodological approach that facilitates the handling of large samples of representations found on different supports-ceramic vessels and boulders. Reliable and unambiguous analytical categories are constructed for the visual resources (toolbox and modes of resolution) used to produce the representations, in order to access the interrelation of gestures, elements and techniques used to resolve the images found on each support. The proposed procedure is demonstrated through an analysis of a sample of 772 representations from the Regional Development Period or Late Intermediate Period (ca. 1200-1400 AD) found on ceramic vessels and boulders in Fiambalá region.

Key words: methodological proposal, representations on rock and ceramics, toolbox, modes of resolution
A lo largo del tiempo, las representaciones plásticas han sido introducidas o descartadas como vía de análisis para contestar diferentes preguntas, de acuerdo a los marcos teóricos vigentes en la disciplina arqueológica e independientemente del tipo de soporte en el que se plasmaran. Aquí enfocamos el análisis de estos materiales sosteniendo que a través de la realización de las manifestaciones plásticas las personas expresaron y fijaron en las rocas o en los objetos cerámicos sus preferencias visuales, configurando mediante ellas una parte significativa de sus modos de ver, imaginar, pensar, experimentar y construir el mundo en que vivían (Gallardo 2005). Desde esta perspectiva, los conjuntos de imágenes ligados a los soportes expresivos escogidos definen un lenguaje visual anclado en un espacio y tiempo particulares y tendrán ciertas características distintivas en función de la red de relaciones, las selecciones y los códigos de diseño compartidos por quienes participen de un mismo entramado social; solo pueden ser interpretadas considerando los contextos prácticos en los que fueron elaboradas, experimentadas, reproducidas, reinterpretadas y utilizadas. En este trabajo presentamos una propuesta metodológica que nos permite aportar a la definición del lenguaje visual plasmado en soportes rupestres y cerámicos del Período de Desarrollos Regionales o Período Intermedio Tardío (ca. 1200-1400 DC) de la región de Fiambalá (Catamarca, Argentina).

\footnotetext{
* Mara Basile, Conicet, Museo Etnográfico Juan B. Ambrosetti (FFyL-UBA), Moreno 350 (1091), Buenos Aires, email: mara_basile@yahoo.com.ar

** Norma Ratto, Museo Etnográfico Juan B. Ambrosetti (FFyL-UBA), Moreno 350 (1091), Buenos Aires, email: nratto@filo.uba.ar
} 
En esta dirección nos orientamos a delinear los recursos visuales utilizados en la realización de cada una de las imágenes. Esto demandó la construcción de dos unidades analíticas (caja de herramientas y modos de resolución) que comprendieron a su vez la definición de variables con estados específicos. Dichas unidades, cuyas características desarrollaremos más adelante, facilitan el manejo de una muestra compuesta por una gran cantidad de representaciones impresas en dos tipos de soportes expresivos de características diferentes: piezas cerámicas y bloques rocosos. Abordar este tipo de comparaciones demanda, por un lado, la definición explícita, no ambigua y replicable de los criterios metodológicos que guían la comparación y, por el otro, la conducción de un tratamiento estadístico multivariado que permita un análisis exploratorio e integral fundamental para el ordenamiento inicial de la variabilidad registrada. El núcleo de nuestra propuesta metodológica consiste en acceder a la interrelación que existe entre los gestos, los elementos y las técnicas utilizadas en la realización de las imágenes en cada uno de los soportes expresivos considerados. Conducir este análisis de las representaciones rupestres y cerámicas de manera conjunta demanda trabajar específicamente al nivel de cada una de ellas aislándolas de las particularidades de sus soportes de ejecución, integrando en esta instancia solo aquellas variables que, siendo equivalentes y factibles de relevar en ambos soportes, nos permiten realizar esta comparación a un mismo nivel analítico. Existen intentos anteriores de abordar la comparación de representaciones plasmadas en soportes expresivos diferentes (roca y cerámica) que sin embargo se basan en formas de clasificación, unidades, métodos analíticos y objetivos diferentes a los que definen nuestra propuesta (ver por ejemplo Prieto \& Santos 2009). ${ }^{1}$

Para ejemplificar nuestro procedimiento metodológico trabajamos con 772 representaciones desplegadas en los bloques grabados del sitio Guanchincito y en los campos decorativos de una muestra de piezas cerámicas enteras, ambos procedentes de nuestra región de estudio en el oeste tinogasteño de la provincia de Catamarca, Argentina.

\section{REPRESENTACIONES EN DIFERENTES SOPORTES: DEFINIENDO LA PROPUESTA METODOLÓGICA}

El primer paso fundamental en cualquier análisis de representaciones plásticas consiste en identificarlas y clasificarlas a partir de la definición de categorías con diferentes grados de inclusión (subclases, clases y conjuntos de clase de motivo, por ejemplo). Este primer paso se lleva a cabo de acuerdo con los criterios empleados por cada equipo de investigación, que se desprenden de los enfoques teórico-conceptuales que definen la mirada sobre estos materiales. En nuestro caso consideramos que cada una de las representaciones constituye una unidad visual y conceptual definida por la percepción de una contigüidad lineal (figs. 1a-b) o de una tensión espacial resultante de la proximidad (figs. 1c-j) (Scott 1962 [1951]; Aschero 1975; Gordillo 2009). ${ }^{2}$ Dichas representaciones son la unidad de entrada a partir de la cual estructuramos el registro de la base de datos para proceder al análisis que permitirá establecer la comparación intersoportes que se propone. a)

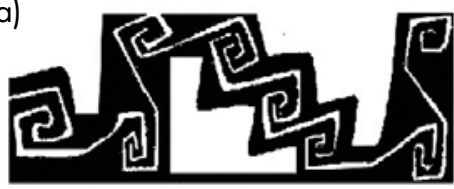

b)

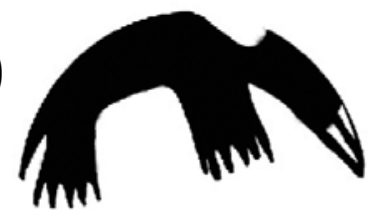

c)

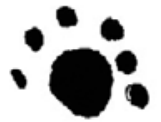

d)

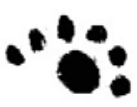

e)

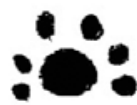

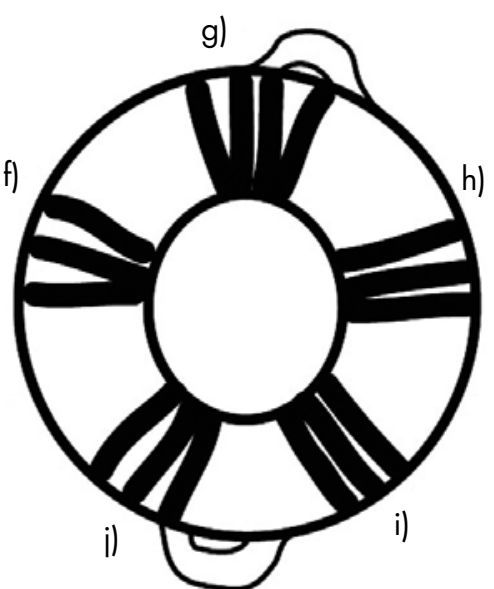

Figura 1. Ejemplos de representaciones definidas por contigüidad lineal (a-b) o tensión espacial (c-j). Figure 1. Examples of representations defined by linear contiguity ( $a-b)$ and spatial tension $(c-j)$. 
Asimismo, entendemos que la producción de cualquier representación visual implica la transformación de materias primas específicas (arcilla, roca, pigmentos) en imágenes, a través de la implementación de ciertas técnicas y de la utilización de elementos e instrumentos particulares. Este proceso creativo demanda inversión de energía, tiempo, habilidades, destreza manual, conocimiento y percepción (Fiore 2007, 2009).

De acuerdo con estos criterios y a fin de aportar a la definición del lenguaje visual del lapso en estudio ( $c a$. 1200-1400 DC) nos propusimos delinear los recursos visuales utilizados para la realización de las imágenes. Esto demandó la construcción de dos unidades analíticas que comprendieron a su vez la definición de variables con estados específicos. La primera se dirigió al interior de cada una de las representaciones para delinear la caja de herramientas (Basile \& Ratto 2009, 2010) utilizada en su configuración. Para ello se determinaron la combinación de las unidades morfológicas (UM) y las formas de articulación (ver infra). El segundo, en contraste, se orientó a definir los modos de resolución de cada una de las representaciones, analizando el tamaño en que se realizaron y las técnicas implementadas en cada caso. La integración de estas variables permitió definir estadísticamente los grupos de recursos visuales utilizados en las representaciones rupestres y cerámicas analizadas.

Consideramos que los tratamientos numéricos multivariados constituyen una herramienta analítica adecuada para integrar las dos unidades de análisis definidas para dar cuenta de recursos visuales utilizados en la realización de las imágenes desplegadas en los distintos soportes. Ahora bien, cualquier método estadístico tiene alcances y limitaciones, debiéndose controlar si las características de las variables utilizadas reúnen las condiciones para la aplicación de tal o cual método. En nuestro caso, se observa que de las cuatro variables mencionadas anteriormente, tres son cualitativas y una es cuantitativa. Ante esta situación el método estadístico de Análisis de Correspondencia Múltiple (ACM) es el procedimiento adecuado para integrar estas variables, dado que los atributos que las definen pueden ser transformados a escalas ordinales jerárquicas (ver infra). A continuación desarrollamos en detalle cada uno de los componentes de nuestra propuesta metodológica.

\section{La caja de herramientas}

El primer paso de nuestra propuesta es definir la caja de herramientas utilizada en la configuración de las imágenes que conforman el repertorio temático de cualquier muestra. Se considera que esta caja de herramientas tiene una dimensión doble dado que, por un lado, involucra una intención gestual particular y, por el otro, una selección de ciertos elementos visuales que manifiestan la existencia de preferencias estéticas y conocimientos compartidos acerca de cómo las cosas deben hacerse en el marco del entramado social particular en que son enseñadas, reforzadas, modificadas, reemplazadas y/u ocultadas (Basile \& Ratto 2009; Basile 2011). Para la definición de la caja de herramientas se construyeron las variables que denominamos: combinación de unidades morfológicas y tipos de articulación.

\section{Combinación de unidades morfológicas}

Todas las representaciones analizadas están compuestas por un número determinado de elementos mínimos que denominamos unidades morfológicas (sensu Aschero 1975) y que remiten a un movimiento y a una intención gestual particular. ${ }^{3}$ Hemos definido ocho tipos de unidades morfológicas básicas (fig. 2) sobre la base de los trabajos de Kandinsky (2007 [1926]), Scott (1962 [1951]) y Aschero (1975, 2012). Estas pueden presentarse en forma aislada pero, en general, la definición de las representaciones resulta de la combinación de una única unidad en sí misma o de más de una de ellas. Para dar cuenta de la variabilidad generamos un número binario que expresa la presencia y la ausencia de cada una de las UM definidas (Basile \& Ratto 2010). Luego, a cada una de las combinaciones expresadas en números binarios se les asigna una ubicación específica y jerárquica dentro del total de las combinaciones posibles, que ascienden a 255 sobre la base de las ocho UM básicas definidas. El ordenamiento jerárquico se realiza considerando como criterio la cantidad de UM combinadas y el tiempo, el grado de control y la precisión que las mismas demandan para su ejecución. En esta dirección, consideramos que realizar un punto (UM1) implica un menor grado de control sobre el trazado y menos inversión de tiempo que la ejecución de un trazo espiralado (UM7). De la misma forma, realizar una imagen a partir de una única UM demandará menor tiempo, control y precisión que la ejecución de una que demande la combinación de varias UM. De esta manera, dicho ordenamiento comienza en el estado 10000000 y finaliza en 11111111 (ver ejemplos en fig. 3). Es factible que no todas las combinaciones posibles estén presentes en la muestra que se analice. Por lo tanto, para integrar esta variable al tratamiento numérico multivariado es necesario renumerar en forma consecutiva las combinaciones registradas respetando su ubicación en la secuencia original. ${ }^{4}$ 


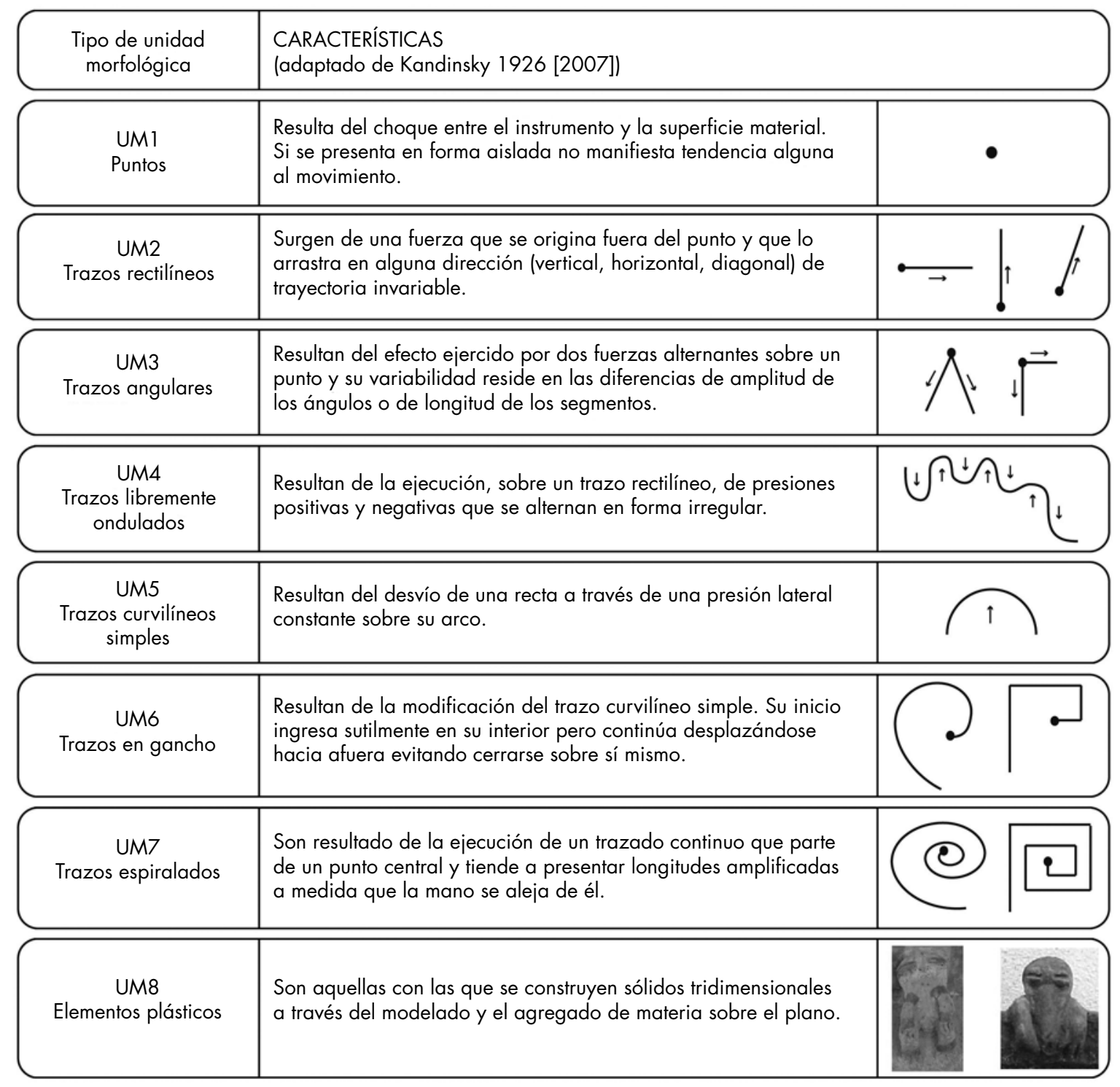

Figura 2. Tipos de unidades morfológicas básicas definidas. Adaptado de Basile 2011.

Figure 2. Definitions of basic morphological units. Adapted from Basile 2011.

Tipos de articulaciones

Para analizar la forma en que las UM se articulan entre sí para configurar las representaciones se definieron diferentes tipos de articulaciones sobre la base de los trabajos de Gardin (1978) y Aschero (2012). Como no todas las representaciones se ejecutan mediante la articulación de diferentes UM, también consideramos su ausencia como un estado de registro para esta variable. De esta manera, se generaron ocho estados que dan cuenta de los tipos de articulaciones básicas y de sus combinaciones (fig. 4). Los diferentes estados se ordenan jerárquicamente para integrarlos al tratamiento numérico multivariado, tomando como criterio la inversión de trabajo diferencial involucrada en la realización de cada tipo de articulación.

\section{Los modos de resolución}

El segundo paso de la propuesta metodológica para el análisis de las imágenes consiste en precisar la forma en que estas se resuelven en cada uno de los soportes. Para la definición de los modos de resolución se construyeron las variables que denominamos: técnicas de ejecución y tamaño de la representación. 

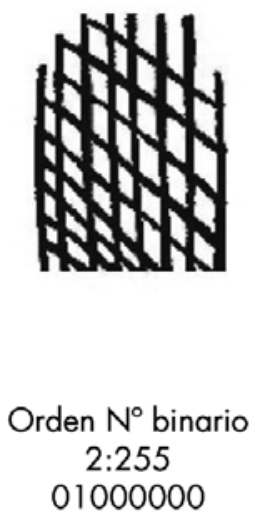

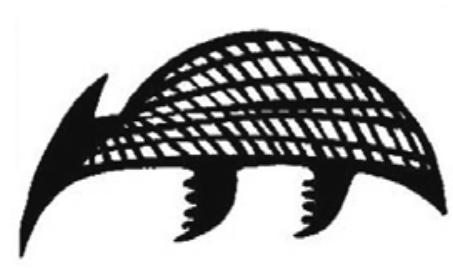

Orden $N^{\circ}$ binario
$45: 255$
01011000

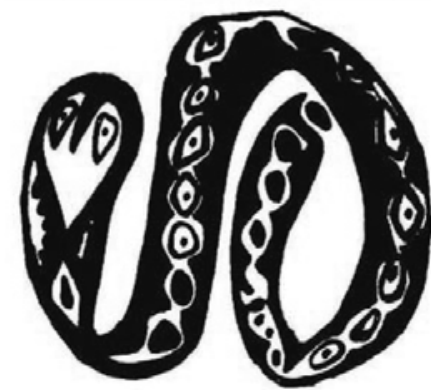

Orden $\mathrm{N}^{\circ}$ binario

163:255

11111000

Figura 3. Ejemplos de jerarquización de combinaciones de unidades morfológicas.

Figure 3. Examples of hierarchization of combinations of morphological units.

Técnicas de ejecución

Las técnicas utilizadas en la modificación de los soportes (modelado, pulido en líneas, inciso, exciso, grabado y pintura) se clasifican considerando que si bien todas implican el uso de instrumentos o elementos particulares (porciones de pasta, puntas, percutores, pinceles o pigmentos), difieren respecto de la cantidad de operaciones que involucran. Por lo tanto, los estados de esta variable presentan un orden jerárquico determinado por la cantidad de operaciones e inversión de trabajo (sensu Fiore 2007) que involucran, poniendo en juego un conocimiento y una habilidad particulares que permiten conjugar los tiempos de ejecución de cada una en el momento correspondiente. Por lo expuesto, consideramos que el modelado es la técnica que se resuelve de manera más sencilla seguida por el pulido en líneas, el inciso o exciso, el grabado y, finalmente, la pintura. De nuevo, estas técnicas pueden presentarse en forma combinada para la realización de representaciones particulares. A fin de dar cuenta de esta variabilidad generamos un número binario que expresara la presencia y la ausencia de cada una de las técnicas. Luego, a cada una de las combinaciones se les asigna una ubicación específica y jerárquica dentro del total de combinaciones posibles, las que ascienden a 31 sobre la base de las cinco técnicas definidas. El ordenamiento jerárquico se realiza considerando como criterio la cantidad de operaciones, los instrumentos y los elementos que demandan para su ejecución, comenzando y finalizando en los estados 10000 y 11111, respectivamente.
Tamaño de la representación

Dado que nuestra propuesta metodológica apunta a relacionar representaciones plasmadas en soportes expresivos (bloques rocosos y piezas cerámicas) que pueden tener dimensiones diferentes, es necesario construir un número índice que dé cuenta de la relación existente entre la superficie de la representación y la del espacio plástico que la contiene.

Para calcular la superficie de cada motivo se considera el alto y el ancho máximo encuadrándolos dentro de una figura virtual de ángulos rectos para definir el área de la representación (Martel 2010).

Por su parte, el cálculo de la superficie de soportes tridimensionales demanda un tratamiento especial. En el caso de los bloques rocosos, en terreno debe determinarse la forma geométrica de la roca (poliedros o cuerpos redondos) a efectos de tomar las medidas necesarias para calcular, con un grado de aproximación confiable, el área disponible para ser intervenida visualmente. Para ello se utilizan las fórmulas del cálculo de áreas de cuerpos, debiéndose tener en cuenta la superficie de apoyo de la roca para corregir el valor obtenido. En el caso de las piezas cerámicas se las encierra dentro de un cilindro calculando su área lateral externa, generando un promedio de los diámetros (base, cuerpo, cuello y boca) para considerar las restricciones o inflexiones de sus contornos. ${ }^{5}$ A diferencia de los bloques, las piezas cerámicas también tienen un espacio interno disponible para su representación. Por lo tanto, en el caso de las piezas abiertas (pucos, escudillas, cuencos) se duplica el área lateral externa calculada ya que toda la superficie interna es accesible para la intervención visual. En 


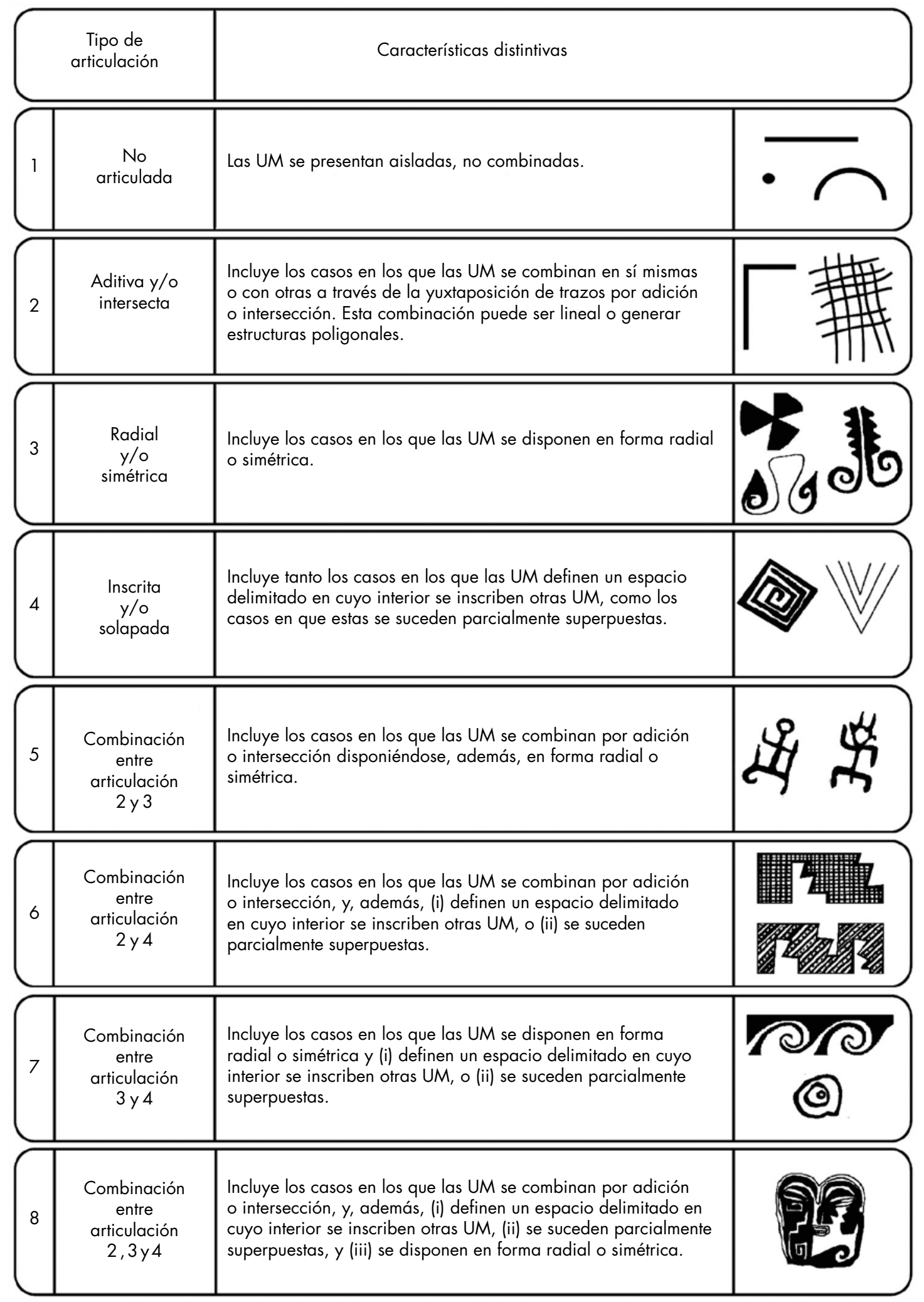

Figura 4. Tipos de articulaciones básicas y combinadas definidas. Adaptado de Basile 2011.

Figure 4. Definitions of basic and combined types of articulations. Adapted from Basile 2011. 
cambio, en el caso de las piezas cerradas (tinajas, ollas) tan solo se considera el área interna del borde y cuello dado que el resto de la superficie interior presenta un acceso limitado para la representación. ${ }^{6}$

Por todo lo expuesto, el tamaño de las imágenes de ambos soportes se expresa en un número índice que se transforma en una variable ordinal en función del rango de intervalo que tenga la muestra en estudio. ${ }^{7}$

\section{Integración de la caja de herramientas y los modos de resolución}

Tal como hemos explicado previamente, las cuatro variables que definen las unidades analíticas caja de berramientas y modos de resolución presentan un ordenamiento jerárquico que da cuenta del incremento progresivo en la inversión de trabajo (sensu Fiore 2007). Esto permite la realización de un tratamiento estadístico multivariado para la integración de estas variables que consistió en la combinación de métodos factoriales (ACM) y Análisis de Conglomerados Jerárquicos (ACJ) (Pardo \& Del Campo 2007).

El ACM no solo permite estudiar las relaciones de interdependencia entre variables cualitativas, sino que también permite conocer cómo está estructurada esa relación, habiendo tenido el método amplia difusión en las ciencias humanas. Con los valores de los ejes factoriales obtenidos al aplicar ACM se realiza un ACJ (Método Ward y distancia Euclidiana). El análisis del dendrograma correspondiente permite determinar la cantidad de grupos de recursos visuales (GRV) que define la muestra, caracterizados por una combinación particular de las cuatro variables interrelacionadas (combinación de UM, tipo de articulación, técnica de ejecución y tamaño de la representación).

En resumen, el tratamiento numérico multivariado permite obtener un primer perfil de la estructura de la muestra de representaciones plásticas que se analiza. Al respecto, el procedimiento detallado es ejemplificado a través del análisis de una muestra de 772 representaciones del PDR o PIT (ca. 1200-1400 DC) desplegadas sobre piezas cerámicas y bloques rocosos de la región de Fiambalá.

\section{LA METODOLOGÍA EN ACCIÓN: EL CASO DE LAS REPRESENTACIONES EN SOPORTES RUPESTRES Y CERÁMICOS DE LA REGION DE FIAMBALA}

Para comenzar a delinear el lenguaje visual mediante la metodología propuesta, analizamos una muestra compuesta por 516 representaciones registradas sobre piezas cerámicas y 256 plasmadas sobre bloques rocosos. Las piezas cerámicas proceden de intervenciones arqueológicas en sitios de la región y/o del relevamiento de colecciones privadas o depositadas en museos. En todos los casos se trata de contextos funerarios de tumbas en cista (Finca Justo Pereira, Finca Istataco y Las Champas) y en urna (Bebé de La Troya), emplazados en diferentes cotas altitudinales del valle mesotérmico de la región de Fiambalá (1350-1900 msnm), ascendiendo la muestra total a 50 piezas (fig. 5) (Basile 2009; Basile \& Ratto 2010; Ratto \& Basile 2010). Para todos estos casos se cuenta con fechados radiocarbónicos que permiten ubicarlas dentro del rango temporal del 1200 a 1400 DC. Estas piezas presentan un repertorio temático que es característico de estos momentos en nuestra área de estudio en el que predominan las volutas, los escalonados, los rectángulos, los trazos ondulados, las espirales, los ganchos, los triángulos, los rastros, las figuras humanas, las lechuzas, los quirquinchos y los ofidios, entre otros (fig. 6).

Por su parte, la muestra de 256 representaciones rupestres procede de 22 bloques de arenisca roja del sitio Guanchincito emplazado también en el valle mesotérmico en cota de 1700 msnm (fig. 5). Las formas predominantes de estos bloques son prismáticas y cilíndricas. Aquí destacan las espirales, los ganchos, los círculos, los trazos rectilíneos, ondulados, los rastros, los camélidos y las figuras humanas (fig. 6). Por las características de las imágenes presentes, la mayoría de ellas fueron adscritas al PDR de la historia regional (Ratto et al. 2000-2002; Ratto et al. 2010; Basile 2010, 2011).

Las 772 representaciones, figurativas (162:772) y no figurativas (610:772), fueron clasificadas en cinco conjuntos de clases, 22 clases y 52 subclases de motivos considerando la propuesta elaborada por Aschero (2006, 2012). ${ }^{8}$ Esta clasificación se basa en definir la diversidad de imágenes (clases) y especificar la variabilidad (subclase) dentro de cada una de las clases, por ejemplo, dentro de la clase "trazos lineales" se incluyen las subclases "trazos simples aislados", "trazos agrupados", "trazos reticulados", "trazos angulares", entre otros. Cabe aclarar que toda clasificación involucra un proceso interpretativo porque implica siempre una doble traducción, de un lenguaje visual a uno textual y de una perspectiva cultural a otra (Velandia 2003). Si bien acordamos en que la simple clasificación de imágenes en términos de semejanza respecto de algún modelo que consideramos referente no ofrece mucho más que una mera sustitución verbal que resulta poco informativa (Black 1983) creemos que es central como punto de partida para definir el repertorio y profundizar después el análisis. 


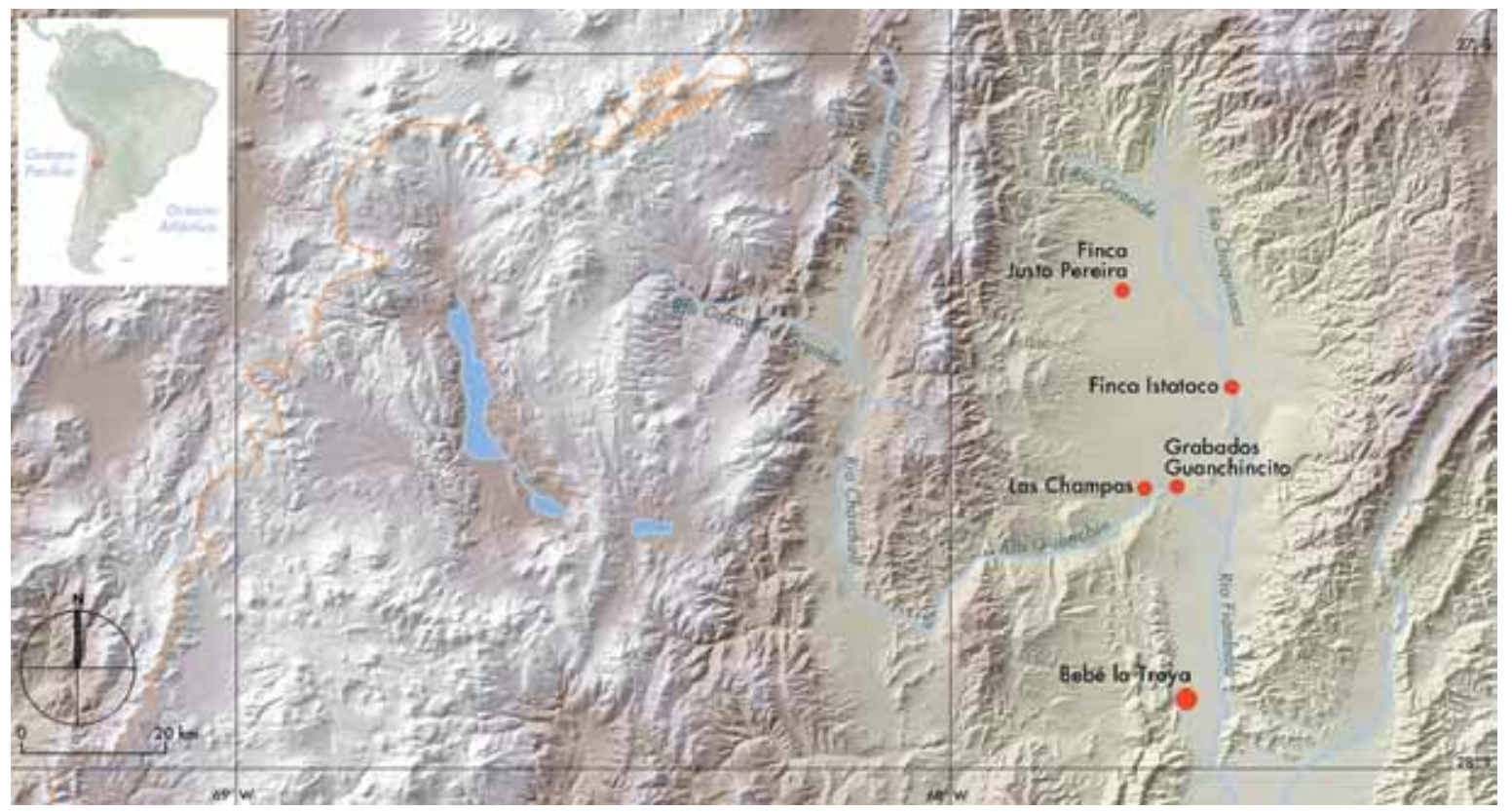

Figura 5. Ubicación de los sitios de procedencia de la muestra de representaciones de la región de Fiambalá. Figure 5. Location of the sites of origin of sample representations of Fiambala region.
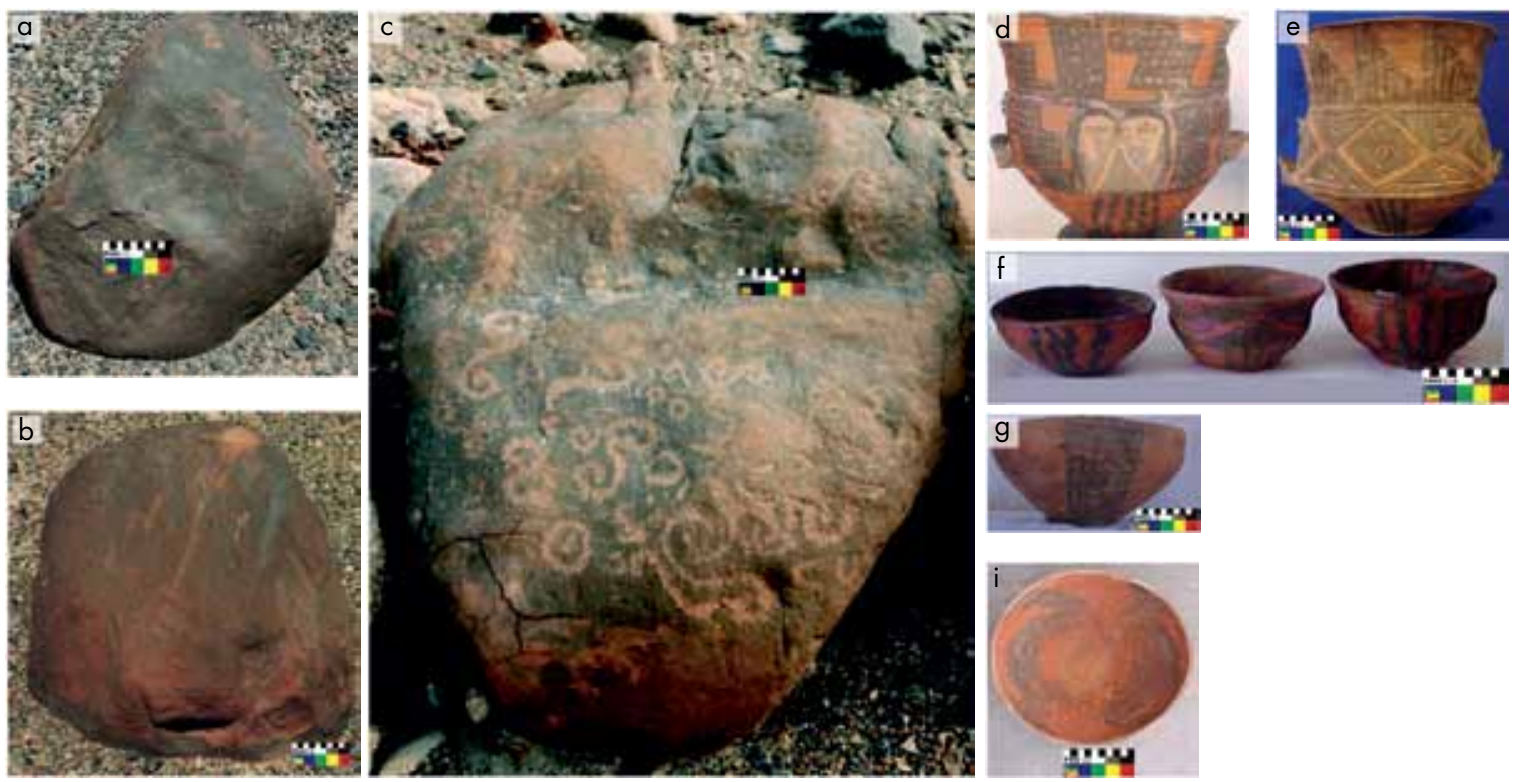

Figura 6. Ejemplos de los bloques grabados de Guanchincito (a-c) y de las piezas cerámicas analizadas (d-i). Figure 6. Some engraved boulders at Guanchincito (a-c) and the ceramic pieces analyzed (d-i).

Esta clasificación tiene el potencial de facilitarnos trabajar en forma flexible y a distintos niveles de inclusión y resolución. Para ilustrar los resultados obtenidos y lograr una mejor expresión gráfica (ver infra) decidimos expresar la interrelación entre las variables de las unidades analíticas (caja de herramientas y modos de resolución) a nivel del conjunto de clases de motivos (fig. 7). Aunque somos conscientes de la alta inclusión y baja resolución de este nivel de la clasificación, se recuerda que el análisis del repertorio temático no es una variable considerada dentro de las unidades analíticas contempladas en esta instancia.

A cada una de las 772 imágenes se le asignó y/o calculó: (i) la combinación de UM registrándose 48 sobre 


\begin{tabular}{l|lll}
\hline $\begin{array}{l}\text { Representaciones } \\
\text { no figurativas primarias } \\
\text { (puntiformes, hoyuelos, trazos lineales, } \\
\text { angulares, círculos, triángulos) }\end{array}$ & $\ddots$ &
\end{tabular}

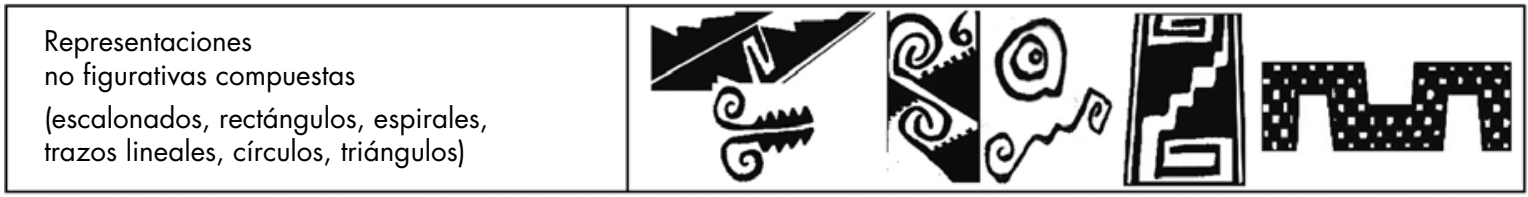
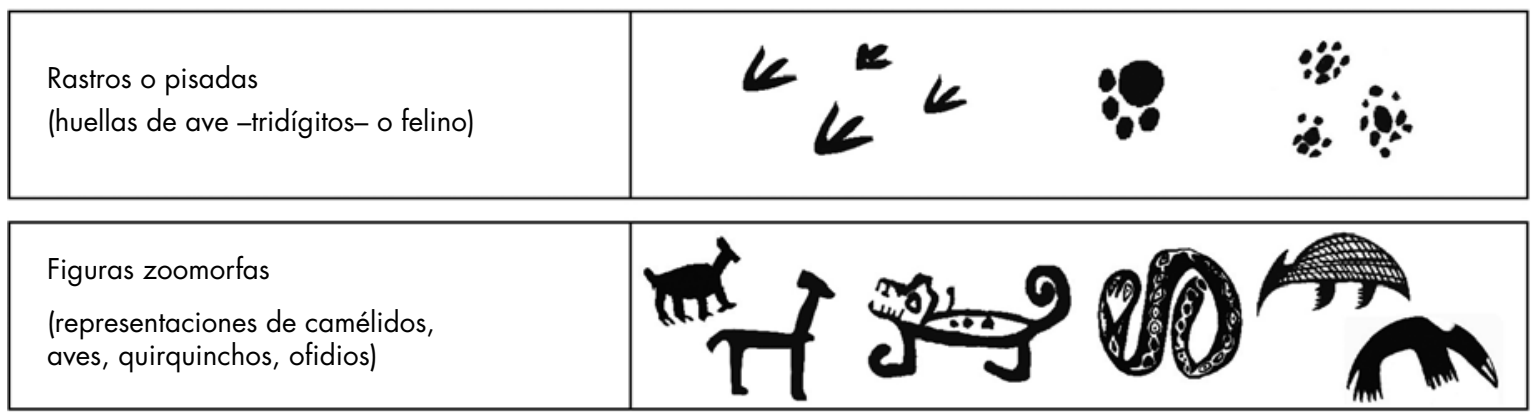

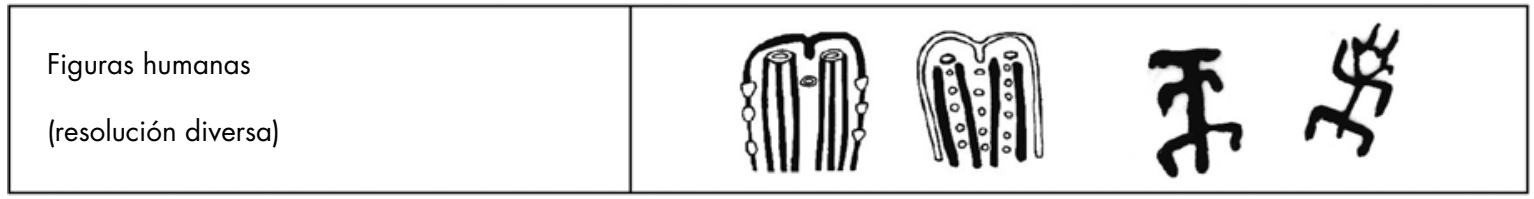

Figura 7. Conjuntos de clases de representaciones definidas.

Figure 7. Classes of representations identified.

las 255 combinaciones posibles; (ii) el tipo de articulación, presentándose los ocho tipos definidos; (iii) la técnica de ejecución registrándose seis sobre las 31 combinaciones posibles, y (iv) el tamaño, generándose ocho clases de intervalos que dan cuenta de su variación en las representaciones. Luego cada una de las cuatro variables fue transformada y posteriormente interrelacionadas mediante análisis estadístico multivariado siguiendo el procedimiento metodológico propuesto (ver supra). El análisis generó tres ejes factoriales donde los dos primeros explican el 95,5\% de la varianza total de la muestra. Se observa que el peso de las variables que definen la caja de herramientas y los modos de resolución se descompone diferencialmente en ambos ejes. Al respecto, el primer eje está definido por la carga positiva de la variable combinación de UM y la negativa de las técnicas de ejecución y el tamaño de la representación. Por su parte, en el segundo eje prevalece la carga positiva de la variable tipo de articulación. Luego de la realización del ACJ, se observa que los ejes se organizan en siete grupos de recursos visuales dentro del espacio factorial (figs. 8-9 y también apoyarse en figs. 2-4) que presentan valores semejantes en función de las variables implicadas en el análisis. Por lo tanto, un grupo de recursos visuales determinado integra aquellas imágenes que tienden a compartir (i) combinaciones de UM, (ii) tipos de articulación, (iii) técnicas de ejecución y (iv) tamaño, dando cuenta de una misma forma de realización de las representaciones. Estos grupos de recursos visuales presentan las tendencias que se explicitan a continuación:

Grupo $N^{\circ} 1$ (122:772). Predominan las imágenes resueltas con UM básicas (trazos lineales o angulares) no articuladas, elaboradas por medio de pintura o grabado, definidas en tamaños medianos a grandes. Incluye el $18,6 \%$ y $10,2 \%$ de las representaciones en soporte cerámico y rupestre, respectivamente.

Grupo $N^{\circ} 2$ (44:772). Incluye imágenes resueltas con un tipo de UM básica (trazos lineales) o combinada (trazos lineales y angulares) que presenta solo dos tipos de articulación, una básica (aditiva-intersecta) y una combinada (aditiva-intersecta + inscrita-solapada). Son exclusivamente pintadas y están realizadas en tamaños mediano-grande y grande. Incluye el $8,5 \%$ de las representaciones en soporte cerámico.

Grupo $N^{\circ} 3$ (255:772). Está compuesto por imágenes resueltas con ciertas UM (trazos curvilíneos simples, en gancho o espiralados), articulación básica (radial-simétrica) o combinada (radial-simétrica + inscrita-solapada), 


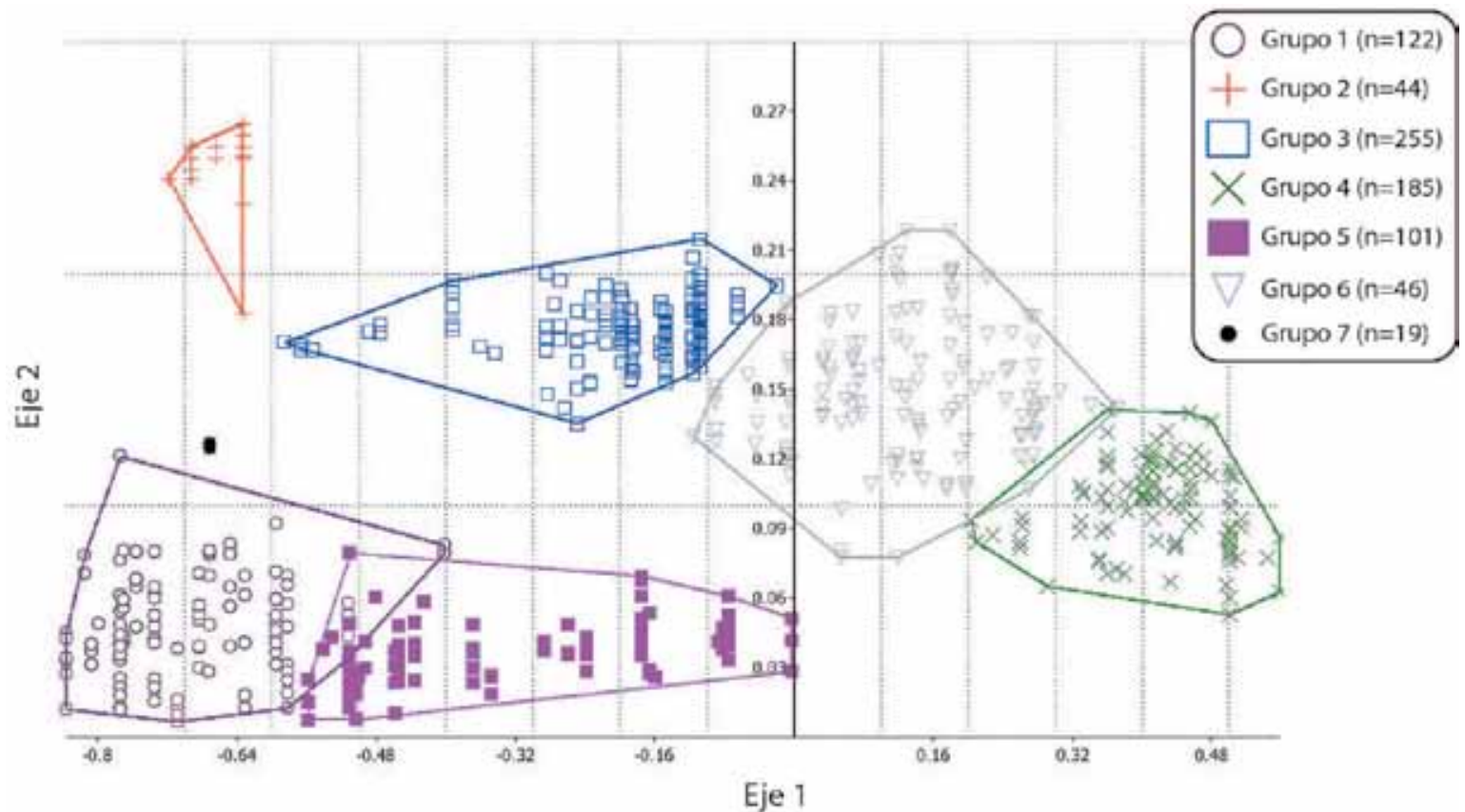

\begin{tabular}{|c|c|c|c|c|c|c|}
\hline \multirow{2}{*}{ Ejes ACM } & \multirow{2}{*}{ Eigenvalue } & \multirow{2}{*}{$\begin{array}{c}\text { \% Varianza } \\
\text { total }\end{array}$} & \multicolumn{4}{|c|}{ Peso de las variables } \\
\cline { 4 - 7 } & & UM & Art. & Técnica & Tamaño \\
\hline 1 & 0.148312 & 76.238 & 0.36435 & -0.12405 & -0.54048 & -0.45328 \\
\hline 2 & 0.037422 & 19.236 & -0.060163 & 0.43426 & -0.1367 & -0.11176 \\
\hline 3 & 0.008803 & 4.525 & -0.004532 & -0.005636 & -0.20976 & 0.12842 \\
\hline
\end{tabular}

Figura 8. Relación de los ejes factoriales 1 y 2 del Análisis de Correspondencia Múltiple. Ploteo en función de los grupos de recursos visuales definidos luego de la aplicación del Análisis de Conglomerados Jerárquicos.

Figure 8. Ratios of factorial axes 1 and 2 of the Multiple Correspondence Analysis. Plotting of groups of visual resources defined after application of the Hierarchical Conglomerates Analysis.

elaboradas por medio de pintura o grabado, en tamaños de pequeño-mediano a grande-muy grande. Este grupo incluye el $31 \%$ y $37,1 \%$ de las representaciones en soporte cerámico y rupestre, respectivamente.

Grupo $N^{o} 4$ (185:772). Incluye imágenes resueltas con las UM combinadas de mayor complejidad de la muestra pero que se realizan tanto con tipos de articulaciones básicas como combinadas. Se documentan todas las técnicas registradas y los tamaños son mediano, mediano-grande y grande. Este grupo incluye el 25,2\% y $21,5 \%$ de las representaciones en soporte cerámico y rupestre, respectivamente.

Grupo $N^{o} 5$ (101:772). Incluye fundamentalmente imágenes resueltas con UM básicas (trazos libremente ondulados) sin articulación. Realizadas por medio de pintura o grabado y en tamaños mediano y medianogrande. Este grupo incluye el $16,5 \%$ y $6,3 \%$ de las representaciones en soporte cerámico y rupestre, respectivamente.
Grupo $N^{\circ} 6$ (46:772). Incluye las imágenes resueltas con determinadas UM básicas (trazos curvilíneos simples y en gancho) que, a diferencia de las incluidas en el Grupo $\mathrm{N}^{\circ} 3$, se presentan sin articulación. Están realizadas por medio de la técnica de grabado y en tamaños pequeños. Este grupo incluye el 17,6\% de las representaciones en soporte rupestre.

Grupo $N^{o} 7$ (19:772). Incluye las imágenes resueltas con UM básicas (puntos) sin articulación, realizadas con la técnica de grabado y en tamaños muy pequeños. Este grupo incluye el 7,4\% de las representaciones en soporte rupestre.

Si estos resultados los relacionamos con los tipos de imágenes registradas, observamos tendencias interesantes que se presentan a nivel de conjuntos de clase de representaciones para garantizar una mejor expresión gráfica (fig. 10). Por un lado, se utilizan iguales cajas de herramientas y modos de resolución para realizar representaciones figurativas y no figurativas, tanto 


\begin{tabular}{|c|c|c|c|c|c|c|c|}
\hline \multirow{2}{*}{$\begin{array}{l}\text { Grupo de } \\
\text { recursos } \\
\text { visuales }\end{array}$} & \multicolumn{4}{|c|}{ Variables combinadas } & \multicolumn{2}{|c|}{ Soporte } & \multirow[b]{2}{*}{ Ejemplos de representaciones } \\
\hline & $\begin{array}{c}\text { Combinación } \\
\text { de UM }\end{array}$ & $\begin{array}{l}\text { Tipo de } \\
\text { articulación }\end{array}$ & Técnica & Tamaño & Roca & Cerámica & \\
\hline 1 & $N^{\circ} 2 / 3$ & Sin articular & \begin{tabular}{|c|} 
Pintura \\
Grabado
\end{tabular} & $\begin{array}{l}\text { md } \\
\text { md-gde } \\
\text { gde }\end{array}$ & $x$ & $x$ & \\
\hline 2 & $N^{\circ} 11,2$ & $\begin{array}{c}\text { Ad-lnt } \\
\text { Ad-Int+lnsc-Sol }\end{array}$ & Pintura & $\begin{array}{l}\text { md-gde } \\
\text { gde }\end{array}$ & & $x$ & \\
\hline 3 & $N^{\circ} 5,6,7$ & $\begin{array}{c}\text { Rad-Sim } \\
\text { Rad-Sim + Insc-Sol }\end{array}$ & \begin{tabular}{|c|} 
Pintura \\
Grabado
\end{tabular} & $\begin{array}{l}\text { pq-md } \\
\text { gde } \\
\text { gde-muy } \\
\text { gde }\end{array}$ & $x$ & $\mathrm{x}$ & \\
\hline 4 & $\begin{array}{c}\mathrm{N}^{\circ} \\
23 / 42 / 14 / \\
15 / 34\end{array}$ & $\begin{array}{c}\text { Ad-IntRad- } \\
\text { Sim+Insc-Sol } \\
\text { Ad-Int+ Rad-Sim+ } \\
\text { Insc-Sol } \\
\end{array}$ & \begin{tabular}{|c|} 
Pintura \\
Grabado \\
Modelado
\end{tabular} & $\begin{array}{l}\text { md } \\
\text { md-gde } \\
\text { gde }\end{array}$ & $x$ & $x$ & \\
\hline 5 & $N^{\circ} 4$ & Sin articular & $\begin{array}{c}\text { Pintura } \\
\text { Grabado }\end{array}$ & $\begin{array}{c}\text { md } \\
\text { md-gde }\end{array}$ & $\mathrm{x}$ & $\mathrm{x}$ & \\
\hline 6 & $N^{\circ} 5 / 6$ & Sin articular & Grabado & $\begin{array}{c}\mathrm{pq} \\
\mathrm{pq}-\mathrm{md}\end{array}$ & $x$ & & \\
\hline 7 & $N^{\circ} 1$ & Sin articular & Grabado & muy pq & $x$ & & : \\
\hline
\end{tabular}

Referencias:

Tipos de articulación: Ad-Int: Aditiva-intersecta; Rad-Sim: Radial-simétrica; Insc-Sol: Inscrita-solapada.

Tamaños de representación: muy pq: muy pequeño; pq: pequeño; pq-md: pequeño-mediano; md: mediano; md-gde: mediano-grande; gde: grande; gde-muy gde: grande-muy grande; muy gde: muy grande.

Figura 9. Síntesis de las tendencias distintivas de cada grupo de recursos visuales y del tipo de representaciones incluidas en cada uno de ellos.

Figure 9. Summary of distinctive trends in each group of visual resources and the type of representations included in each.

primarias como compuestas. ${ }^{9}$ Por el otro, las representaciones no figurativas primarias y compuestas son las que presentan la mayor variabilidad con respecto a las unidades analíticas consideradas, ya que estas imágenes se distribuyen en seis y cuatro de los siete grupos definidos, respectivamente.

En síntesis, el análisis exploratorio realizado nos permite vislumbrar, por una parte, que imágenes diferentes se resuelven por medio de los mismos recursos visuales (definidos por el uso de cajas de herramientas y modos de resolución similares), presentándose en forma conjunta en los mismos grupos. Por otra, que un mismo tipo de imágenes puede resolverse por medio de diversas combinaciones de UM, articulaciones, en tamaños y a través de técnicas distintas, distribuyéndose en grupos diversos. De esta manera, nos habilita a señalar, en función de la muestra analizada, que en el oeste tinogasteño y para el lapso considerado (ca. 12001400 DC), si bien existen imágenes que se plasman con mayor frecuencia en un soporte (roca o cerámica) y no 


\section{Grupos de recursos visuales}

Soporte de representación: Cerámica [516:772]

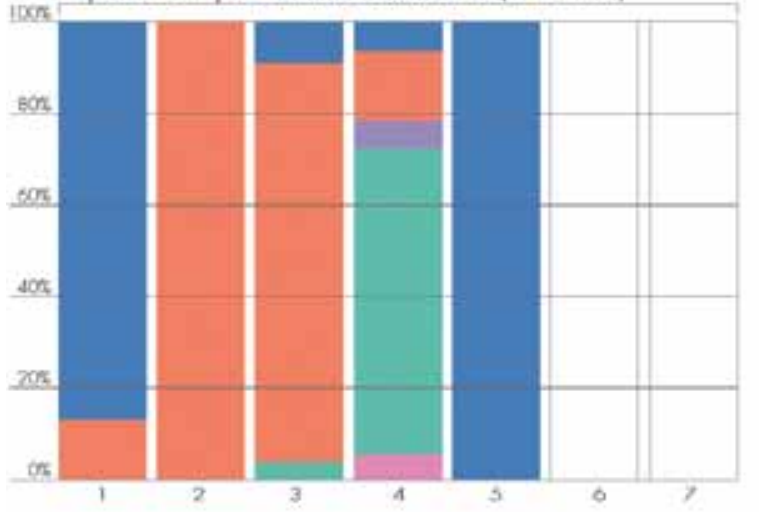

Soponte de representación: Bloque (256:772)

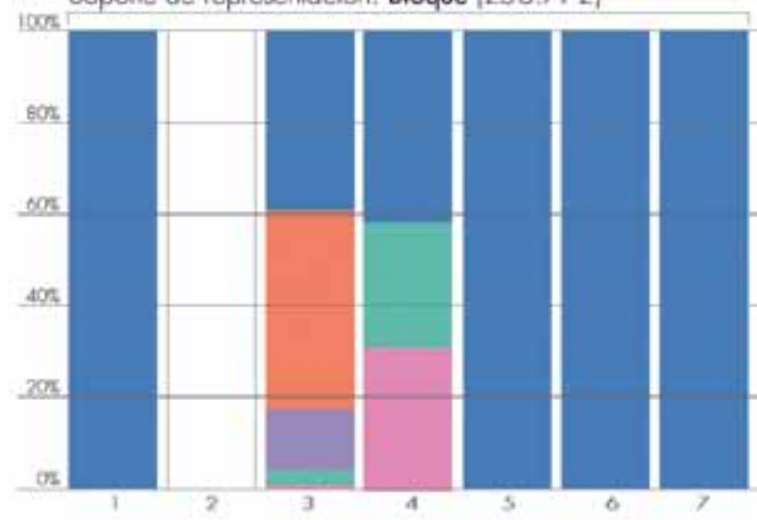

\begin{tabular}{|c|c|c|c|c|}
\hline \multirow{2}{*}{\multicolumn{2}{|c|}{ Conjunto de clases de representación }} & \multicolumn{2}{|c|}{ Tipo de soporte } & \multirow[t]{2}{*}{ Total } \\
\hline & & Cerámica & Bloque & \\
\hline No figurativas primarias & $\mathrm{NFgP}$ & 191 & 150 & 341 \\
\hline No figurativas compuestas [ & $\mathrm{NFgC}$ & 217 & 53 & 270 \\
\hline Rastros o pisadas & R.P & 8 & 17 & 25 \\
\hline Figuras zocmorfas & IFZ & 93 & 18 & 111 \\
\hline \multirow[t]{2}{*}{ Figuras humanas } & $F H$ & 7 & 18 & 25 \\
\hline & Total & 516 & 256 & 772 \\
\hline
\end{tabular}

Figura 10. Relación entre los grupos de recursos visuales definidos y los conjuntos de clase de representaciones plasmadas en cada soporte. Figure 10. Ratios of the visual resources defined and classes of representations depicted on each support.

en otro, existe una unidad que reside justamente en la similitud de las formas de resolución de estas imágenes.

\section{CONCLUSIONES}

El objetivo central de este trabajo fue presentar una propuesta metodológica que define unidades analíticas confiables y no ambiguas en base a criterios que, al estar explícitos resultan replicables, permitiendo comparar muestras compuestas por una gran cantidad de representaciones plasmadas en soportes expresivos diferentes. Dicha propuesta conlleva una construcción de los datos que posibilita el tratamiento numérico de las variables que dan cuenta de los recursos visuales (caja de herramientas y modos de resolución) utilizados en la realización de las representaciones. Este análisis exploratorio e integral facilitó el ordenamiento inicial de los datos que constituye un paso fundamental para organizar la gran variabilidad registrada. Además, tiene la potencialidad de aportar a la definición de las regularidades decorativas propias de cada región a partir del análisis realizado sobre piezas cerámicas enteras, permitiendo posteriormente la integración de las representaciones documentadas sobre material cerámico fragmentario. ${ }^{10}$
Asimismo, facilita la inclusión de imágenes plasmadas sobre soportes diferentes de los rupestres y cerámicos (textiles, vegetales, entre otros) contribuyendo de esta manera a delinear los lenguajes visuales regionales.

En el ejemplo desarrollado trabajamos el análisis de los grupos de recursos visuales al nivel de los conjuntos de clases de representaciones, sabiendo que estos empaquetan la variabilidad del repertorio temático de la muestra. Sin embargo, dado que la unidad de registro es cada representación clasificada a nivel de subclases y clases, la metodología propuesta permite desarrollar y profundizar el análisis a distintos grados de resolución dentro de cada uno de los grupos definidos.

Los procedimientos de construcción e interrelación de las variables y sus estados aportan pero no cubren todas las aristas que intervienen en la definición de los lenguajes visuales. Dado que nuestra unidad de análisis comparativa en esta instancia fue la representación y no la forma en que estas se combinan dentro de un espacio plástico específico, quedaron fuera del análisis la forma en que se estructuraron y utilizaron los espacios plásticos definidos por cada soporte. Nuestro desafío es construir nuevas variables que fortalezcan la metodología propuesta ampliando las que conforman las denominadas caja de herramientas y modos de resolución de 
las representaciones para contribuir a la definición de la multidimensionalidad de los lenguajes visuales que circulan en un espacio y un tiempo determinados. Sin embargo, dado que el foco del trabajo fue la integración de las imágenes plasmadas en dos soportes expresivos contrastantes -no solo en términos de materia prima, sino también de dimensiones, visibilidad, movilidad y localización en el paisaje-, la selección de las variables que se incorporen debe limitarse específicamente a aquellas que permitan llevar adelante esa comparación. ${ }^{11}$

RECONOCIMIENTOS A las coordinadoras del simposio "Cómo vemos: El saber-hacer metodológico frente a la materialidad visual en arqueología" del XVIII Congreso Nacional de Arqueología Chilena, por invitarnos a participar. A Carlos Aschero por su gran generosidad. A Dolores Carniglia por ayudarnos con las traducciones. A los evaluadores anónimos de este trabajo por sus valiosas sugerencias y comentarios. La investigación fue realizada en el marco de los proyectos UBACYT F-139 y PICT-2007-01539 dirigidos por la Dra. N. Ratto.

\section{NOTAS}

${ }^{1} \mathrm{El}$ análisis realizado por estos autores es, a diferencia del que aquí proponemos, exclusivamente cualitativo y no involucra la aplicación de métodos estadísticos multivariados, orientándose a caracterizar los patrones de regularidad espacial que se materializan en la decoración cerámica y rupestre (Prieto \& Santos 2009).

${ }^{2} \mathrm{El}$ concepto de contigüidad lineal remite a la definición de imágenes que se recortan del fondo por el delineado de un contorno continuo que las unifica, mientras que el de tensión espacial define el efecto de la atracción resultante de la proximidad existente entre elementos de la imagen que si bien no están unidos por contigüidad lineal, son percibidos por los observadores como una unidad que se segrega del fondo (Scott 1951). A modo de ejemplo, en la figura 1c se observa que los círculos si bien no están conectados, la tensión resultante de su proximidad y la segregación espacial existente entre cada uno de ellos define que se los perciba como tres unidades diferentes, tres huellas felínicas, en este caso concreto.

${ }^{3} \mathrm{Si}$ bien la continuidad de los trazados resultantes es variable dependiendo, por ejemplo, del tiempo de repetitividad de la acción, del instrumental utilizado y de la dureza del soporte sobre el que se ejecutan, nos interesa particularmente la intencionalidad gestual existente detrás de los mismos

${ }^{4}$ Por ejemplo, suponiendo un caso ideal donde las combinaciones posibles expresadas en números binarios adquieran la ubicación $\mathrm{N}^{\circ} 5,30,45,60,65,72,78,88,89$ y 90 , la renumeración se realiza del $\mathrm{N}^{\circ} 1$ al 10 respetando el orden de la secuencia original.

${ }^{5}$ La fórmula para el cálculo del área lateral del cilindro es: $S=[(2 \pi r) \times(h+r)]$.

${ }^{6}$ Este cálculo se puede realizar más ajustadamente utilizando integrales pero nos parece que la alternativa propuesta es más simple y ofrece, de todas maneras, un procedimiento replicable.

${ }^{7}$ En los casos en los que se comparan tamaños de representaciones muy diferentes es posible que antes de clasificar los atributos de esta variable sea necesario normalizar la muestra.

${ }^{8}$ Esta propuesta fue elaborada por Carlos Aschero para el análisis del arte rupestre de la vecina región de Antofagasta de la Sierra ubicada al norte del Departamento de Tinogasta (Catamarca).

${ }^{9}$ Cabe aclarar que el criterio para diferenciar las representaciones no figurativas primarias de las compuestas fue que las primeras se resuelven mediante una única $\mathrm{UM}$, mientras que las segundas se definen con la combinación de dos o más UM.
${ }^{10}$ Se aclara que los materiales fragmentarios incluidos en el análisis tienen que reunir ciertas características, particularmente deben presentar puntos característicos que permitan inferir la forma y el tamaño de las piezas.

${ }^{11}$ En esta dirección, en un trabajo reciente de una de nosotras (Basile 2011) se sumó al análisis una nueva variable, contorno de representación, que considera la forma en que las imágenes se recortan del fondo tomando en cuenta su contenido que puede ser lineal, pleno o relleno. Creemos que esto permite seguir afinando esta metodología.

\section{REFERENCIAS}

Aschero, C., 1975. Motivos y objetos decorados del sitio precerámico Inca Cueva 7 (provincia de Jujuy). Antiquitas 20-21: 2-7, Buenos Aires.

- 2006. De cazadores y pastores. El arte rupestre de la modalidad río Punilla en Antofagasta de la Sierra y la cuestión de la complejidad en la Puna Meridional argentina. En Tramas en la piedra. Producción y usos del arte rupestre, D. Fiore \& M. M. Podestá, Eds., pp. 103-140. Asociación Amigos del Instituto Nacional de Antropología (AINA), World Archaeological Congress (WAC) y Sociedad Argentina de Antropología. Buenos Aires: Altuna Impresores.

- 2012 Ms. Arte rupestre, contexto y sociedad en el desierto puneño. Tesis doctoral en preparación, Facultad de Filosofía y Letras, Universidad de Buenos Aires.

BASILE, M., 2009. Recorriendo trazos. Un aporte a la definición del estilo decorativo Belén. Revista Arqueología 15: 13-40, Buenos Aires.

- 2010. Lugares grabados en la roca. Contrastes y contactos entre los bloques de Guanchincito y Suri Potrero (Fiambalá, Catamarca). En Actas del XVII Congreso Nacional de Arqueología Argentina, Tomo II, pp. 863-868, Mendoza.

— 2011. Continuidades y rupturas en las representaciones plásticas del Formativo ( $c a .200 \mathrm{AD}$ ) a la ocupación incaica (ca. $1480 \mathrm{AD}$ ) en la región de Fiambalá (pcia. de Catamarca). Tesis de Doctorado, Facultad de Filosofía y Letras, Universidad de Buenos Aires.

BASILE, M. \& N. RATTO, 2009. Interacting images. Analysis of rock-art paintings and engravings in western Tinogasta from 2500 to 1500 BP (Catamarca, Argentina). Fundhamentos IX (4): 12691283. Piauí: Fundação Museu do Homem Americano.

— 2010. Imágenes sobre rocas del sudoeste tinogasteño (Catamarca, ca. 2500 y el 1300 AP). Arqueología 17: 13-34, Buenos Aires.

Black, M., 1983. ¿Cómo representan las imágenes? En Arte, percepción y realidad, E. H. Gombrich, J. Hochberg \& M. Black, Eds., pp. 127-169. Buenos Aires: Editorial Paidós.

Fiore, D., 2007. The economic side of rock art. Concepts on the production of visual images. Rock Art Research 24 (2): 149-160.

-2009. La materialidad del arte. Modelos económicos, tecnológicos y cognitivo-visuales. En Perspectivas actuales en arqueología argentina, R. Barberena, K. Borrazzo \& L. A. Borrero, Comps., pp. 121-154. IMHICIHU. Buenos Aires: Editorial Dunken.

GALLARDO, F., 2005. Arte rupestre, contenido cultural de la forma e ideología durante el Formativo Temprano en el río Salado (desierto de Atacama, Chile). TAPA 33: 37-52.

GARDIN, J. C., 1978. Code pour l'analyse des ornements. Paris: Editions du Centre National de la Recherche Scientifique.

Gordillo, I., 2009. Organización socioespacial y religión en Ambato, Catamarca. El sitio ceremonial de La Rinconada. British Archaeological Reports, International Series 7, Oxford.

Kandinsky, W., 2007 [1926]. Punto y línea sobre el plano. Contribución al análisis de los elementos pictóricos. La Plata: Terramar Ediciones.

MarTel, A., 2010. Arte rupestre de pastores y caravaneros. Estudio contextual de las representaciones rupestres durante el período Agroalfarero Tardío (900-1480 DC) en el Noroeste Argentino. 
Tesis doctoral inédita, Facultad de Filosofía y Letras, Universidad de Buenos Aires.

Pardo C. E. \& P. C. Del Campo, 2007. Combinación de métodos factoriales y de Análisis de Conglomerados en R: el paquete FactoClass. Revista Colombiana de Estadística Vol. 30 (2): 231-245.

Prieto, P. \& M. SANTOS, 2009. Propuesta metodológica para el análisis de los códigos decorativos: comparando piedras y cerámica. Estudios Atacameños 37: 123-138.

RatTo, N. \& M. BASILE, 2010. Una historia de encuentros de imágenes en vasijas del oeste tinogasteño (Catamarca, Argentina). Trabajo presentado en el "Taller de trabajo: Diseño, estilo e interacción social en arqueología”. Cajón del Maipo, 22 al 25 de julio, Santiago de Chile.
RATTO, N.; M. ORGAZ \& S. CALETTT, 2000-2002. Relevamiento arqueológico del campo de grabados de Guanchincito (Fiambalá, depto. Tinogasta, Catamarca). Cuadernos 19: 551-572, Buenos Aires.

RatTo, N.; M. Orgaz \& L. Coll, 2010. Paisajes agrícolas prehispánicos en el oeste tinogasteño, Catamarca. En Actas del XVII Congreso Nacional de Arqueología Argentina, Tomo II, pp. 419-424, Mendoza.

ScotT, R., 1962 [1951]. Fundamentos del diseño. Buenos Aires: Editorial Lerú.

VELANDIA, C., 2003 Análisis estructuralista de la iconografía funeraria en la cultura arqueológica de Santa María, Argentina. Icónica Antiquitas 1 . <www.ut.edu.co/ma/iconica/v1n1/velandia/index. html> [Acceso: 10 de agosto de 2005]. 